\title{
Reliability of Echocardiography in Assessing Cardiac Output
}

\author{
A Comparative Study with a Dye Dilution Technique* \\ Wolfgang Kiowski, Otelio S. Randall, Thomas G. Steffens, and Stevo Julius \\ University of Michigan Medical Center, Ann Arbor, USA
}

Summary. Because of the potential benefits from a noninvasive technique in assessing cardiac output, we compared cardiac output estimates from left ventricular echocardiograms with results obtained simultaneously by a standard technique, dye dilution in 10 healthy normal volunteers. During rest, cardiac outputs by echocardiographic and dye dilution techniques were reproducible and not significantly different. Increases in cardiac output produced by intravenous infusion of isoproterenol $(15 \mathrm{ng} / \mathrm{kg} / \mathrm{min}$ for 4 min) were accurately estimated by echocardiography in subjects whose stroke volume increased less than $40 \%$, but were significantly underestimated when stroke volume increased more than $40 \%$. Decreased cardiac output produced by intravenous propranolol $(0.2 \mathrm{mg} / \mathrm{kg})$ was comparable by both methods. Although echocardiography accurately estimated mean cardiac output for the group it over- or underestimated cardiac output in individual subjects. We propose that echocardiography can reliably estimate cardiac output in groups at rest and when stroke volume changes less than $40 \%$.

Key words: Cardiac output - Non-invasive - Echocardiography - Dye dilution

\section{Echocardiographische Bestimmung des Herzminutenvolumens: Vergleich mit einer Farbstoffverdiinnungsmethode}

Zusammenfassung. Einer nicht invasiven Methode zur akkuraten Bestimmung des Herzminutenvolumens (HMV) käme eine große Bedeutung zu. Wir verglichen deshalb aus links-ventriculären Echocardiogrammen bestimmte mit gleichzeitig mittels Farbstoffverdünnungsmethode (Cardiogreen) bestimmten

* This study was supported in part by grants from the Michigan Heart Association

Offprint requests to: Dr. W. Kiowski (address see page 1120)
HMV in 10 normalen Versuchspersonen. Unter Ruhebedingungen war das HMV mit beiden Methoden reproduzierbar und nicht signifikant verschieden. Anstiege des HMV nach intravenöser Infusion von Isoproterenol $(15 \mathrm{ng} / \mathrm{kg} / \mathrm{min}$ über $4 \mathrm{~min})$ wurden mittels Echocardiographie zuverlässig nur bei Probanden erfaßt, bei denen das Schlagvolumen weniger als $40 \%$ anstieg. Bei größeren Anstiegen wurde der Anstieg des HMV signifikant unterschätzt. Ein erniedrigtes HMV nach intravenöser Injektion von Propranolol $(0,2 \mathrm{mg} / \mathrm{kg})$ wurde von beiden Methoden gleichermaßen erfaßt. Obwohl das HMV mittels Echocardiographie für das Untersuchungskollektiv nicht signifikant von den Farbstoffverdünnungswerten verschieden war, wichen die echocardiographisch bestimmten HMV bei einzelnen Probanden deutlich von den Farbstoffverdünnungswerten $a b$. Unsere Ergebnisse zeigen, daß die links-ventriculäre Echocardiographie zur Bestimmung des HMV in Gruppen und bei Änderungen des Schlagvolumens von weniger als $40 \%$ benutzt werden kann.

Schliusselwörter: Herzminutenvolumen - nicht-invasiv - Echocardiographie - Farbstoffverdünnungstechnik

M-mode left ventricular echocardiograms have been used to calculate ventricular volumes, stroke volume and cardiac output $[1,6-8,15-18]$. The problems inherent in the technique and the underlying geometric assumptions have been reviewed [13, 19-21]. The method has the obvious advantage of being non-invasive and, therefore, qualifies for serial measurements without risk or discomfort to the subject. Because of this advantage it has been used in clinical investigation as a convient tool to estimate cardiac output $[3,20]$. However, the value of echocardiographic estimation of cardiac output was investigated in only a few studies $[1,16]$ and it is desirable to obtain 
more data on the accuracy of this method. Because of the potential usefulness of a reliable, non-invasive method for estimating cardiac output in clinical investigation, we assessed the accuracy of echocardiography by comparing echocardiographic to simultaneously obtained dye dilution results in normal volunteers.

\section{Subjects and Methods}

Ten healthy male paid volunteers were studied. The protocol of the study was reviewed and accepted by this institution's Committee for Human Use in Clinical Investigation. All subjects read and signed a detailed informed consent.

The studies were performed between 8-10:00 A.M. Cardiac output was measured simultaneously by dye dilution and echocardiography four times in each subject: firstly, after resting in recumbency for 20 min after all catheters were placed, secondly, after recumbent rest for an additional $10 \mathrm{~min}$, thirdly, after intravenous infusion of $15 \mathrm{ng} / \mathrm{kg} / \mathrm{min}$ of isoproterenol for $4 \mathrm{~min}$, and finally, $10 \mathrm{~min}$ after a slow intravenous injection of $0.2 \mathrm{mg} / \mathrm{kg}$ of propranolol. One subject did not receive propranolol because of a history of asthma.

The dye dilution technique for measuring cardiac output utilizing Cardiogreen and a Gilford densitometer is routinely used in this laboratory [10]. In short, a 4-F caliber flow directed Swan-Ganz catheter was introduced percutaneously into an antecubital vein and advanced to the right atrium for delivery of dye. A $2 \frac{1}{2}$ inch 18-gauge Longdwell Teflon catheter (Becton-Dickinson) was placed in one brachial artery to allow continuous withdrawal of blood through the densitometer. Cardiac output curves and lead II of the electrocardiogram were inscribed using a Hewlett Packard 4578 A polygraph. Heart rate was derived from the ECG and stroke volume was calculated by dividing cardiac output by heart rate.

Left ventricular echocardiograms were obtained as described by Popp and Harrison [18] using a Smith Kline Instruments Ekoline 20 ultrasonic unit with an Aerotech transducer $(2.25 \mathrm{MHz}, 13 \mathrm{~mm}$ diameter) and a Smith Kline Instruments Ekoline 21 strip chart recorder. The left ventricular internal end-diastolic diameter $\left(D_{4}\right)$ was measured as the distance between the left ventricular posterior wall and the interventricular septum at the peak of the $R$-wave of the $E C G$, and the end-systolic diameter $\left(D_{s}\right)$ as the shortest possible distance during a cardiac cycle. Ten consecutive beats obtained during the recording of dye dilution curves were analyzed and the mean was used for calculating volumes and cardiac output using the following formulae [18]:

End-diastolic volume $(\mathrm{EDV})=\left(\mathrm{D}_{\mathrm{f}}\right)^{3}$

End-systolic volume $\left.(\mathrm{ESV})={ }_{\mathrm{c}} \mathrm{D}_{\mathrm{s}}\right)^{3}$

Stroke volume $(\mathrm{SV}$ ECHO) $=$ EDV - ESV

Cardiac ouput $(\mathrm{CO} \mathrm{ECHO})=$ SV ECHO X heart rate

All echocardiographic recordings were measured by the same observer without having knowledge of the dye dilution results.

Data are presented as the mean \pm standard error of the mean (SEM) as an index of dispersion. The t-test for paired and unpaired data was used to test the significance of differences. Linear correlation coefficients were computed by way of the least square method.

\section{Results}

Echocardiographic measurements of left ventricular dimensions as well as echocardiographically estimated cardiac outputs in comparison with dye dilution measurements are listed in Table 1. The agreement between both methods under the various conditions of the experiment is illustrated in Fig. 1.

\section{Measurements Under Resting Conditions}

Calculations of cardiac outputs from echocardiograms gave results similar to the dye dilution determinations under resting conditions and there was no significant difference between the means obtained by the different techniques. Correlation coefficients were computed and the $\mathrm{r}$ value at Rest 1 was $0.55(p=0.1)$

Table 1. Echocardiographic measurements of left ventricular dimensions and comparison of cardiac output as estimated by echocardiography with dye dilution measurements

\begin{tabular}{|c|c|c|c|c|c|c|c|c|c|c|c|c|c|c|c|c|}
\hline \multirow{3}{*}{$\begin{array}{l}\text { Pat. } \\
\text { No. }\end{array}$} & \multicolumn{4}{|l|}{ Rest 1} & \multicolumn{4}{|c|}{ Rest 2} & \multicolumn{4}{|c|}{ Isoproterenol } & \multicolumn{4}{|c|}{ Propranolol } \\
\hline & \multirow{2}{*}{$\begin{array}{l}\mathrm{SD} \\
(\mathrm{mm})\end{array}$} & \multirow[t]{2}{*}{ DD } & \multicolumn{2}{|c|}{ Cardiac output } & \multirow{2}{*}{$\frac{\mathrm{SD}}{(\mathrm{mm})}$} & $\mathrm{DD}$ & \multicolumn{2}{|c|}{ Cardiac output } & \multirow{2}{*}{$\begin{array}{l}\mathrm{SD} \\
(\mathrm{mm})\end{array}$} & \multirow[t]{2}{*}{$\mathrm{DD}$} & \multicolumn{2}{|c|}{ Cardiac output } & \multirow{2}{*}{$\begin{array}{l}\mathrm{SD} \\
(\mathrm{mm})\end{array}$} & DD & \multicolumn{2}{|c|}{ Cardiac output } \\
\hline & & & $\begin{array}{l}\text { Echo } \\
\text { (1/min) }\end{array}$ & Dye & & & $\begin{array}{l}\text { Echo } \\
\text { (1/min) }\end{array}$ & Dye & & & $\begin{array}{l}\text { Echo } \\
\text { (1/min) }\end{array}$ & Dye & & & $\begin{array}{l}\text { Echo } \\
(1 / \mathrm{min})\end{array}$ & Dye \\
\hline 1 & 35.3 & 47.8 & 2.75 & 4.75 & 34.1 & 49.5 & 3.92 & 4.91 & 28.9 & 48.8 & 5.52 & 10.00 & 35.5 & 50.9 & 3.85 & 4.48 \\
\hline 2 & 34.5 & 48.1 & 3.93 & 7.07 & 34.1 & 48.5 & 4.46 & 7.11 & 26.5 & 48.9 & 7.08 & 9.23 & 32.7 & 47.6 & 3.50 & 6.50 \\
\hline 3 & 35.2 & 49.9 & 5.16 & 7.12 & 31.4 & 50.4 & 6.60 & 6.90 & 25,1 & 50.9 & 8.82 & 9.40 & - & - & - & - \\
\hline 4 & 32.4 & 53.4 & 9.22 & 8.36 & 32.5 & 54.2 & 10.24 & 9.68 & 27.4 & 54.4 & 14.04 & 13.72 & 33.6 & 53.6 & 6.27 & 5.79 \\
\hline 5 & 38.9 & 55.5 & 7.92 & 5.69 & 36.1 & 54.7 & 7.95 & 6.40 & 26.8 & 50.4 & 8.16 & 11.18 & 36.2 & 53.3 & 6.24 & 5.35 \\
\hline 6 & 35.3 & 51.1 & 5.37 & 5.83 & 34.2 & 50.7 & 6.05 & 5.31 & 28.7 & 50.3 & 9.33 & 13.03 & 35.0 & 47.5 & 3.66 & 5.74 \\
\hline 7 & 34.3 & 47.8 & 4.14 & 5.60 & 34.2 & 47.5 & 4.03 & 5.63 & 26.6 & 47.4 & 7.36 & 9.03 & 30.4 & 47.8 & 4.14 & 3.99 \\
\hline 8 & 32.5 & 50.8 & 5.86 & 5.05 & 33.2 & 51.9 & 6.50 & 5.03 & 26.5 & 52.9 & 9.84 & 9.30 & 37.4 & 52.7 & 5.09 & 3.83 \\
\hline 9 & 31.5 & 48.7 & 7.08 & 7.49 & 31.6 & 49.4 & 6.94 & 7.13 & 26.1 & 48.7 & 8.80 & 13.05 & 31.9 & 48.6 & 5.27 & 4.42 \\
\hline 10 & 29.2 & 47.2 & 5.29 & 5.03 & 27.8 & 47.0 & 5.48 & 4.75 & 19.4 & 46.6 & 7.51 & 7.33 & 32.1 & 47.7 & 4.22 & 3.70 \\
\hline Mean & 33.8 & 50.0 & 5.67 & 6.21 & 32.9 & 5.04 & 6.22 & 6.29 & 26.2 & 49.9 & 8.65 & 10.53 & 33.9 & 49.9 & 4.65 & 4.87 \\
\hline$\pm \mathrm{SEM}$ & 0.84 & 0.90 & 0.62 & 0.32 & 0.75 & 0.86 & 0.61 & 0.48 & 0.88 & 0.79 & 0.72 & 0.67 & 0.81 & 0.93 & 0.37 & 0.33 \\
\hline
\end{tabular}

$\mathrm{SD}=$ Systolic diameter $\mathrm{DD}=$ Diastolic diameter, $\mathrm{Echo}=$ Echocardiography, Dye $=$ Dye dilution technique 


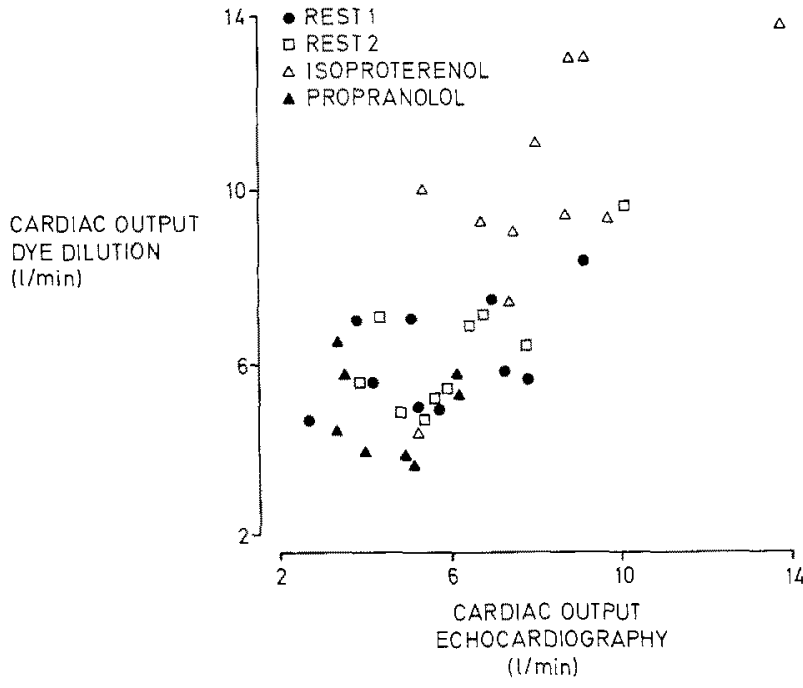

Fig. 1. Scatter plot of 39 cardiac output measurements by echocardiography against simultaneously obtained dye dilution values of ten normal volunteers under various conditions (for details see Subjects and Methods)

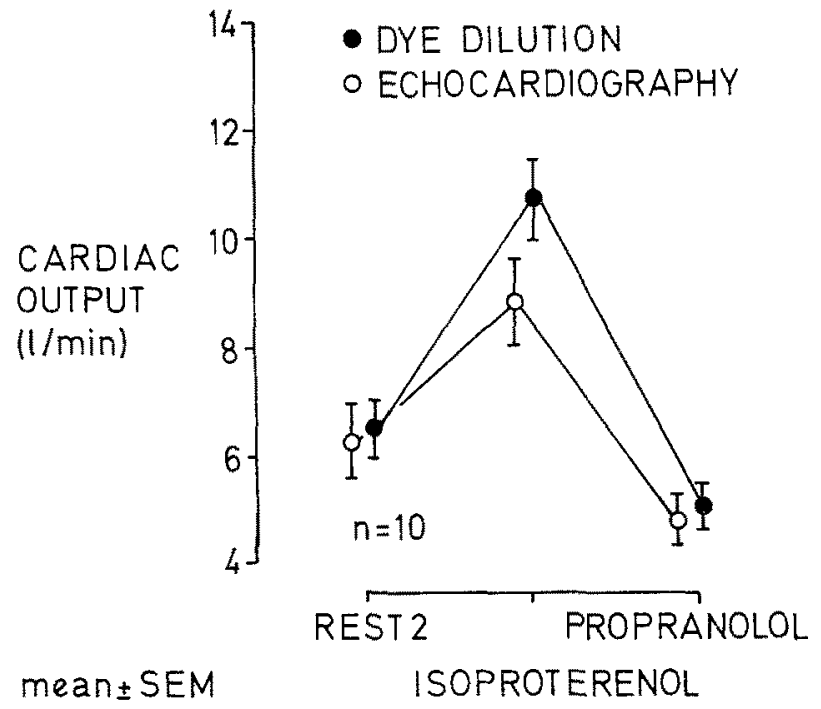

Fig. 2. Cardiac output changes induced by infusion of isoproterenol (15 $\mathrm{ng} / \mathrm{kg} / \mathrm{min}$ for $4 \mathrm{~min}$ ) and propranolol $(0.2 \mathrm{mg} / \mathrm{kg})$ as estimated by dye dilution and echocardiography

Table 2. Effect of isoproterenol ( $15 \mathrm{ng} / \mathrm{kg} / \mathrm{min}$ for $4 \mathrm{~min})$ on resting heart rates and stroke volumes as determined by echocardiography and dye dilution

\begin{tabular}{|c|c|c|c|c|}
\hline & \multicolumn{2}{|l|}{ Rest 2} & \multicolumn{2}{|l|}{ Isoproterenol } \\
\hline & Dye dilution & Echocardiography & Dye dilution & Echocardiography \\
\hline $\begin{array}{l}\text { Heart Rate } \\
\text { (Beats/min) }\end{array}$ & \multicolumn{2}{|c|}{$65.8 \pm 3.0$} & \multicolumn{2}{|c|}{$80.3 \pm 3.6$} \\
\hline Stroke Volume (ml) & $95.4 \pm 4.95$ & $93.1 \pm 5.92^{2}$ & $131.6 \pm 6.86$ & $106.8 \pm 5.42^{b}$ \\
\hline
\end{tabular}

Values are means \pm S.E.M. The significance levels of differences between echocardiographic and dye dilution results (Student's $t$-test) are indicated

a No significant difference

$p<0.01$

and at Rest 2, $0.72(p=0.02)$. Two measurements at rest were made so that the reproducibility of both methods could be compared. The coefficients of variation ${ }^{1}$ were $8.9 \%$ and $8.4 \%$ for dye dilution and echocardiography, respectively. The coefficients of correlation between the two sets of resting measurements were $r=0.94$ and $r=0.85$ for dye dilution and echocardiography, indicating adequate and comparable reproducibility for both methods.

\section{Measurements After Pharmacological Interventions}

The effects of the infusions of isoproterenol and propranolol on cardiac output are shown in Fig. 2.

\footnotetext{
1 Coefficient of variation $=\frac{\text { standard deviation of the mean difference }}{\text { combined mean }} \times 100$
}

Both techniques were able to detect the increase in cardiac output induced by isoproterenol but echocardiography underestimated this increase by $18 \%$ as compared to dye dilution measurements. This difference, which was not statistically significant $(p=$ 0.07 ), was due to an underestimation in stroke volume (Table 2). Since this underestimation was not present in all subjects, an attempt was made to characterize the factor(s) responsible for the lack of agreement between the methods in some subjects.

In our subjects, echocardiography was able to follow increases in stroke volume up to $40 \%$ above the resting values as determined by dye dilution (Group 1). Increases greater than this (Group 2) were underestimated. Figure 3 illustrates the ability of echocardiography for detecting increases in cardiac 
Table 3. Comparison of cardiac output and stroke volume measurements by dye dilution and echocardiography in two groups of subjects with different inotropic responses to isoproterenol infusion $(15 \mathrm{ng} / \mathrm{kg} /$ $\min$ for $4 \mathrm{~min}$ ). Group 1 subjects increased stroke volume $<40 \%$ and Group 2 subjects $>40 \%$ above the resting value

\begin{tabular}{|c|c|c|c|c|}
\hline & \multicolumn{2}{|l|}{ Group $1(n=5)$} & \multicolumn{2}{|l|}{ Group $2(\mathrm{n}=5)$} \\
\hline & $\begin{array}{l}\text { Cardiac output } \\
(1 / \mathrm{min})\end{array}$ & $\begin{array}{l}\text { Stroke volume } \\
\text { (ml) }\end{array}$ & $\begin{array}{l}\text { Cardiac output } \\
\text { (1/min) }\end{array}$ & $\begin{array}{l}\text { Stroke volume } \\
\text { (ml) }\end{array}$ \\
\hline Dye Dilution & $9.74 \pm 1.06$ & $117.6 \pm 8.09$ & $11.31 \pm 0.77$ & $145.6 \pm 7.06$ \\
\hline Echocardiography & $8.96 \pm 1.30^{\mathrm{a}}$ & $107.3 \pm 9.53^{\mathrm{a}}$ & $8.33 \pm 0.75^{b}$ & $106.3 \pm 6.42^{\mathrm{b}}$ \\
\hline
\end{tabular}

Values are means \pm S.E.M. The significance levels of differences between echocardiographic and dye dilution measurements (Student's $t$-test) are indicated

a No significant difference

b $p<0.025$

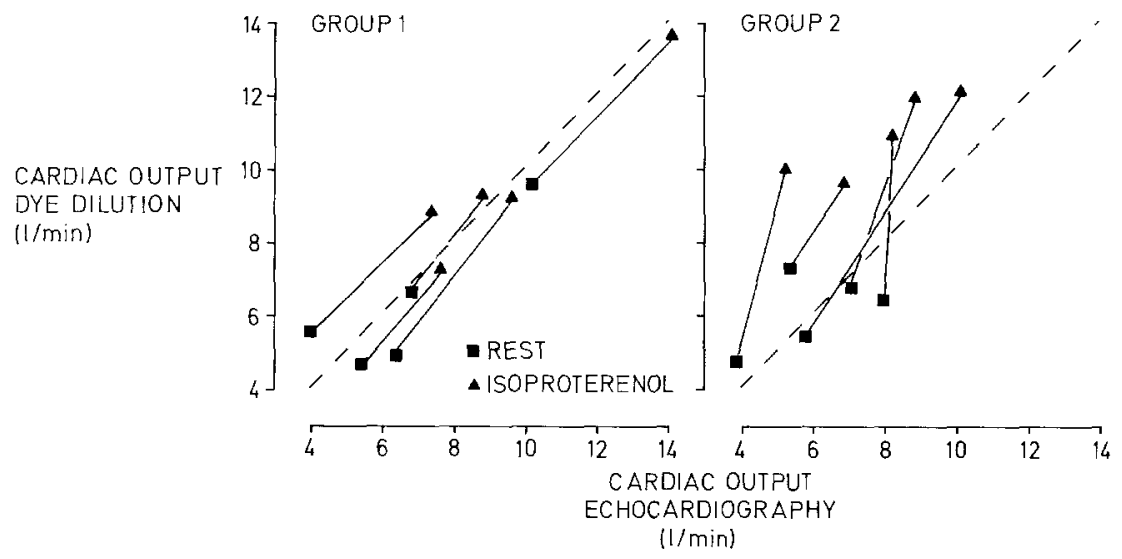

Fig. 3. Simultaneous cardiac output measurements by echocardiography and dye dilution before ( $\mathbf{\omega})$ and after ( $\mathbf{\Lambda})$ isoproterenol infusion $(15 \mathrm{ng} / \mathrm{kg} / \mathrm{min}$ for $4 \mathrm{~min}$, in two groups of subjects. Group 1 subjects exhibited less than $40 \%$ increase in stroke volume in response to isoproterenol while Group 2 subjects increased stroke volume by more than $40 \%$. A line connecting a resting and an isoproterenol-stimulated value parellel to the line of identity (broken line) indicates equal increases of cardiac output by both methods. A steeper slope than that of the line of identity indicates an underestimation of the increase by echocardiography output in comparison with dye dilution. In subjects of Group 1, echocardiographically determined increases in cardiac output were in proportion to those obtained by dye dilution, whereas echocardiography clearly underestimated the effect of isoproterenol in subjects of Group 2. In Group 1 no significant differences between stroke volume and cardiac output measurements by either method were found, while in Group 2, the values were significantly different (Table 3). The groups did not differ regarding the chronotropic effect of isoproterenol as heart rates after isoproterenol infusion were comparable, $82.0 \pm$ 4.5 and $78.3 \pm 5.4$ beats $/ \mathrm{min}$. The increase in cardiac output in Group 1 did not reflect changes in heart rate only, but also a significant increase in stroke volume from a mean of $87.2 \mathrm{ml}$ at rest to $107.3 \mathrm{ml}$ $(p<0.01)$.

Infusion of propranolol decreased cardiac output below resting values in all subjects. This was readily detected by both methods and there was no significant difference between the means obtained by either method, however, no correlation between the methods was found following propranolol.

\section{Discussion}

The acceptability of any method depends upon the fulfillment of three basic requirements: accuracy, reproducibility and ability to detect changes. In the present report, these parameters were assessed by comparing echocardiographic results to those obtained by an accepted standard technique, dye dilution [2]. Simultaneous recording of dye dilution and echocardiographic measurements and the use of the rapidly completed dye dilution technique precluded spontaneous variations of cardiac output as a source of error in our results.

Under resting conditions and after beta-blockade with propranolol, the mean cardiac output by the two methods was not significantly different, whereas after isoproterenol echocardiography underestimated cardiac output by an amount that nearly reached statistical significance. However, unlike for the total group mean, the agreement between the methods was less reliable for each individual since echocardiography underestimated cardiac output in some cases and overestimated it in others. This is reflected in the 
lack of an overall correlation between the methods, being significant only at Rest 2 . This lack of correlation and, thus, precision was still present when regression equations derived by others $[8,21]$ were applied to our data. However, these regression equations are thought to be particularly helpful in the determination of either small or large ventricular volumes. It is not surprising therefore, that the application of these formulae did not improve precision in our groups of healthy volunteers with normal sized hearts.

Inspite of the individual differences between the absolute cardiac output values obtained by the different techniques their determination by echocardiography proved to be a reproducible measurement with a coefficient of variation for duplicate measurements comparable to that of the dye dilution technique, $8.4 \%$ and $8.9 \%$, respectively. Therefore, changes in cardiac output and stroke volume greater than approximately $10 \%$ should be detectable by left ventricular echocardiograms.

In the present study, isoproterenol increased and propranolol decreased stroke volume and cardiac output by more than $10 \%$ in each subject as determined by dye dilution. Ventricular echocardiograms were able to detect decreases in cardiac output produced by propranolol and increases after isoproterenol infusion when the change in stroke volume was less than $40 \%$ of the resting value. There was no agreement between the methods when stroke volume increased by more than $40 \%$. The reason for this is not readily apparent.

Faster heart rates as a cause for the lack of agreement in subjects with stroke volume increases of more than $40 \%$ were considered and dismissed, since heart rates were comparable in all subjects regardless of the stroke volume response to isoproterenol. A possible explanation could be that a very strong inotropic effect of isoproterenol alters the normal anatomical relations of the left ventricle and therefore ventricular dimensions might be obtained form different anatomical sites.

However, since most physiological stimuli result in stroke volume changes of $10-40 \%$ [4], echocardiography could be used to evaluate the hemodynamic effects of these as well as of pharmacological stimuli, the inotropic effects of which are known to be mild.

Several previous studies have compared left ventricular volumes and cardiac output determined by echocardiography and angiocardiography $[1,7,8,15]$. When patients with ventricular asynergy were excluded, significant correlations were found between ventricular volumes [7, 8] and cardiac output $[1,15]$ obtained by the two techniques. These correlations, however, were due to the presence of only a few cases with extremely high cardiac output thus creating a wide range of cardiac output values. Although a wide range tends to improve a correlation statistically, this does not neccessarily mean a better agreement between the methods. If, for example, the range of of cardiac output values in two of these studies [1, $15]$ is narrowed to normally expected resting values of less than $10 \mathrm{l} / \mathrm{min}$, the reported significant correlation coefficients of 0.70 and 0.81 decrease to 0.004 and 0.3 , respectively. The mean cardiac output values by both methods, however, were not significantly different (calculated from Table 2 of each study), an observation also noted in the present study.

Studies comparing cardiac output determined by echocardiography and direct measuring techniques are rare. A report by Pombo et al. showed a highly significant correlation between cardiac output determined by echocardiography and dye dilution [16]. This correlation coefficient however, was derived from 36 pairs of observations on nine patients and therefore was not based on truly independent observations [14]. If, for example, all 39 pairs of observations in our study are used to calculate a correlation coefficient, a value of $r=0.76, p<0.001$ is obtained. This would suppose a greater accuracy of echocardiography than what would appear from any single set of measurements. It would though be due only to the presence of low and high cardiac outputs following the administration of propranolol and isoproterenol (Figure 1). Thus this way of analyzing the data, although resulting in statistically highly significant correlations, obscures the true accuracy of echocardiography.

In conclusion, our results suggest that echocardiography is adequate in assessing the mean cardiac output in groups and in detecting changes in cardiac output from physiological or mild pharmacological interventions. M-mode echocardiography seems to be less useful when accuracy of the absolute cardiac output values is needed in an individual. Also can it be used with confidence only in subjects known to have normally contracting hearts. More sophisticated techniques, such as twodimensional echocardiography $[5,9,11]$ or different approaches [12] may prove more reliable for determining absolute cardiac output at rest and under other conditions.

\section{References}

1. Belenkie I, Nutter DO, Clark DW, McCraw DE, Raizner AE (1973) Assessment of left ventricular dimensions and function by echocardiography. Am J Cardiol 31:755-762

2. Bloomfield DA (1974) Dye curves: The theory and practice of indicator dilution. University Park Press, Baltimore

3. Burggraf GW, Barker JO (1974) Left ventricular volume changes after amyle nitrite and nitroglycerine in man as measured by ultrasound. Circulation 49:136-143 
4. Clarke DH (1975) Exercise physiology. Prentice-Hall, Englewood Cliffs, pp 94-96

5. Eaton LW, Maughan WL, Shoukas AA, Weiss JL (1979) Accurate volume determination in the isolated ejecting canine left ventricle by two-dimensional echocardiography. Circulation $60: 320-326$

6. Feigenbaum H, Wolfe SB, Popp RL, Haine CL, Dodge HT (1969) Correlation of ultrasound with angiocardiography in measuring left ventricular diastolic volume (abstr). Am J Cardiol 23:111

7. Feigenbaum H, Popp RL, Wolfe SR, Troy BL, Pombo JF, Haine CL, Dodge HT (1972) Ultrasound measurement of the left ventricle. Arch Intern Med 129:461-467

8. Fortuin NJ, Hood WP, Sherman ME, Craige E (1971) Determination of left ventricular volumes by ultrasound. Circulation $44: 575-584$

9. Gehrke J, Leeman S, Priddie RB (1975) Non-invasive left ventricular volume determination by two-dimensional echocardiography. Br Heart J 37:911-916

10. Julius S, Amery A, Whitlock LS, Conwas J (1967) Influence of age on the hemodynamic reponse to exercise. Circulation $36: 222-230$

11. Kisslo J, Ramm OT von (1976) Cardiac imaging using a phased array ultrasound system. II Clinical technique and application. Circulation 53:262-267

12. Lalani AV, Kee SJK (1976) Echocardiographic measurement of cardiac output using the mitral valve and aortic root echo. Circulation 54:738-743

13. Linhart JW, Mintz GS, Segal BL, Kawai B, Kotler MN (1975) Left ventricular volume measurements by echocardiography: Fact or fiction? Am J Cardiol 36:114-118

14. Morrison DF (1967) Multivariate statistical methods. McGrawHill, New York, pp 94-103

15. Pombo JF, Troy BL, Russell RO (1971) Left ventricular vo- lumes and ejection fraction by echocardiography. Circulation $43: 480-490$

16. Pombo JF, Russell RO, Rackley CE, Foster GL (1971) Comparison of stroke vlume and cardiac output determination by ultrasound and dye dilution in acute myocardial infarction. Am J Cardiol 27:630-635

17. Popp RL, Wolfe SB, Hirata T, Feigenbaum H (1969) Estimation of right and left ventricular size by ultrasound. Am J Cardiol 24:523-530

18. Popp RL, Harrison DC (1970) Ultrasonic cardiac echography for determining stroke volume and valvular regurgitation. Circulation $41: 493-502$

19. Popp RL, Alderman EL, Brown OR, Harrison DC (1973) Sources of error in calculation of left ventricular volumes by echocardiography (abstr). Am J Cardiol 31:152

20. Sullivan MD, Schoenberger AA, Ratts TE, Palmer ET, Samaha JK, Mance CJ, Muirhead EE (1979) Short-term therapy of severe hypertension: Hemodynamic correlates of the antihypertensive response in man. Arch Inter Med 139:114-119

21. Teichholz LE, Kreulen T, Herman MV, Gorlin R (1976) Problems in echocardiographic volume determinations: Echocardiographic-angiographic correlations in the presence or absence of asynergy. Am J Cardiol 37:7-11

Received March 10, 1980

Accepted April 15, 1981

Dr. W. Kiowski

Department of Internal Medicine

Kantonsspital

CH-4031 Basel

Switzerland 